Available online on 15.02.2020 at http://jddtonline.info
Open Access to Pharmacentical and Medical Research
unrestricted non-commercial use, provided the original work is properly cited

Open Access

Short Communication

\title{
Nigella sativa seed extract protects against cadmium-induced cardiotoxicity in rats
}

\author{
*Uchendu Ikenna Kingsley, Nnedu Ebuka Bitrus, Ekeigwe Ifeoma Blessing \\ Department of Medical Laboratory Science, University of Nigeria, Enugu, Nigeria
}

\begin{abstract}
Objective: The aim of this study is to investigate the protective effects of methanolic extract of Nigella sativa (MENS) (Black seed) against cardiotoxicity of cadmium in albino rats.

Methods: Twenty five (25) male albino rats, weighing (150-170g), were randomly grouped into five groups: A-E. Group B (Negative Control) received intraperitoneal administration of cadmium chloride $\left(\mathrm{CdCl}_{2}, 5 \mathrm{mg} / \mathrm{kg}\right)$ only, group $\mathrm{C}$ received $\mathrm{CdCl} 2$ and low dose $\mathrm{MENS}(300 \mathrm{mg} / \mathrm{kg}$, oral), group D received $\mathrm{CdCl}_{2}$ and high dose MENS $\left(600 \mathrm{mg} / \mathrm{kg}\right.$, oral), group E (Positive control) received $\mathrm{CdCl}_{2}$ and Vitamin C (200mg/ $\mathrm{kg}$, oral), for 7 days. No treatment was administered to group A (Normal control). Cardiac injury was assessed by measuring serum levels of Aspartate aminotransferase (AST), Lactate dehydrogenase (LDH) and Creatine kinase (CK-MB) using standard methods. The heart was harvested for histopathological examination.

Results: $\mathrm{CdCl}_{2}$ induced significant cardiotoxicity with marked elevation in the levels of biochemical markers of cardiac functions ( $\mathrm{p}<0.05$ or $\mathrm{p}<0.01$ ); these were however attenuated by MENS. Histopathological examination of the heart sections supported the biochemical findings. Conclusion: Nigella sativa seed extract is potentially cardioprotective against harmful chemical toxins such as cadmium.
\end{abstract}

Keywords: Cadmium, $\mathrm{CdCl}_{2}$, Nigella sativa, Medicinal food, cardiotoxicity

Article Info: Received 24 Nov 2019; Review Completed 10 Jan 2020; Accepted 23 Jan 2020; Available online 15 Feb 2020

Cite this article as:

Uchendu IK, Nnedu EB, Ekeigwe IB, Nigella sativa seed extract protects against cadmium-induced cardiotoxicity in rats, Journal of Drug Delivery and Therapeutics. 2020; 10(1-s):174-177 http://dx.doi.org/10.22270/jddt.v10i1-s.3868

*Address for Correspondence:

Uchendu Ikenna Kingsley Department of Medical Laboratory Science, University of Nigeria, Enugu State, Nigeria

\section{INTRODUCTION}

Ingestion or exposure to chemicals (toxins) poses a serious health risk. Early intervention against cellular or biochemical changes induced by such events is vital to help prevent organ damage. Cadmium chloride $\left(\mathrm{CdCl}_{2}\right)$, recognized as an experimental toxin, is known to be highly cardiotoxic. Cadmium toxicity poses adverse effects on target organs such as the kidney, lungs, liver, testes, bones and the cardiovascular system. ${ }^{1}$

Despite all studies performed to date, therapy choices for heart injuries are very few. Foods or plants with medicinal value have proven to be most useful in the treatment of diseases in most of the developing countries, and they provide important sources of most of the world's pharmaceutical; thus they have served a valuable starting material for drug development. ${ }^{2}$ Recently, beneficial effects of medicinal plants in human health have received considerable attention. These beneficial effects have been partly attributed to the phytochemical compounds which possess antioxidation. We evaluated the protective effects of methanolic extract of Nigella sativa seed against cadmiuminduced cardioxicity in rats.

\section{MATERIALS AND METHODS}

\section{Collection of plant material}

Fresh samples of Nigella sativa seeds were obtained from local market in Enugu, Nigeria. It was authenticated by a consultant taxonomist at the Department of Plant Science and Biotechnology, University of Nigeria, Nsukka, and a voucher specimen was deposited at the herbarium with reference number UNH 662 for future reference.

\section{Preparation of methanolic extracts of Nigella sativa (MENS)}

Nigella sativa seeds were dried and shaded from sun light, then powdered with a grinder. The extracts were prepared using Babaei et al. ${ }^{3}$ method with minor modifications. Five hundred gram $(500 \mathrm{~g})$ of $N$. sativa powder was macerated with 2 litres of analytical grade of absolute (100\%) methanol (as methanolic extract) for seventy two (72) hours. The mixture was stirred in an Erlenmeyer flask for twenty four (24) hours by a shaker. At the end of the extraction, the extract was filtered through a Whatman filter (Whatman Clifton, NJ, USA). Finally, using a waterbath set at $30^{\circ} \mathrm{C}$, the solvent evaporated, and $4 \mathrm{~g}$ of dried methanolic extracts was obtained. This was reconstituted in distilled water, used to 
prepare the required concentration, and stored at $4{ }^{\circ} \mathrm{C}$ until when needed.

\section{Phytochemical analysis of Nigella sativa}

Preliminary phytochemical screening of $N$. sativa was carried out at Department of Pharmacognosy, Faculty of Pharmaceutical Science, University of Nigeria Nsukka. Procedures outlined by Trease and Evans ${ }^{4}$ were employed for the analyses.

\section{Chemical reagents and drugs}

The chemicals used in the study were of analytical grade and include absolute methanol, for plant extraction, and Cadmium chloride salt for induction of cardiotoxicity, and were purchased from Ogbete main market, Enugu. Drug used includes vitamin C (Alpha Pharmaceuticals, Enugu, Nigeria). AST assay kit was purchased from Randox Laboratory (UK); CKMB ELISA kit was from Elabscience (Texas, USA); and LDH ELISA kit from MyBioscience (San Diego, USA).

\section{Preparation of vitamin C solution}

Stock concentrations $(20 \mathrm{mg} / \mathrm{ml})$ of vitamin C were prepared and used for the research.

\section{Preparation of cadmium chloride solution}

Eighty milligram $(80 \mathrm{mg})$ of cadmium salt $\left(\mathrm{CdCl}_{2}\right)$ was dissolved in distilled water and made up to $100 \mathrm{ml}$ in a measuring cylinder to give a stock concentration of $0.8 \mathrm{mg} / \mathrm{ml}$.

\section{Induction of cardiotoxicity}

Acute cardiac injury was induced in each animal by intraperitoneal injection with cadmium chloride solution (5mg/kg), daily for 7 days.

\section{Animals}

A total of twenty five (25) adult albino rats, weighing (150$170 \mathrm{~g}$ ), were obtained from the animal house of the College of Veterinary Medicine, University of Nigeria. The animals were housed under standard condition. The animals were kept under observation for about 14 days before the onset of the experiment for acclimatization. The experimental protocol was approved by the institution animal ethics committee of the University of Nigeria Teaching Hospital (UNTH/CSA. 524/VOL. 19).

\section{Experimental Design}

Group A: (normal Control): No treatment was administered to this group.

Group B: (Negative Control): received $\mathrm{CdCl}_{2}$ (5mg/kg, i.p) only for 7 days.

Group C: received $\mathrm{CdCl}_{2}$ and low dose MENS $(300 \mathrm{mg} / \mathrm{kg}$, oral) for 7 days.

Group D: received $\mathrm{CdCl}_{2}$ and high dose MENS $(600 \mathrm{mg} / \mathrm{kg}$, oral) for 7 days.
Group E (Positive control): received $\mathrm{CdCl}_{2}$ and Vitamin C (200mg/kg, oral) for 7 days.

\section{Sample collection}

After 7 days, $6 \mathrm{ml}$ of blood was collected from the axillary vein under chloroform anesthesia. The blood was dispensed into a plain container, allowed to clot at room temperature, spun at 5,000 r.p.m for $5 \mathrm{~min}$; serum was separated and cryopreserved for analysis of cardiac biomarkers (CK-MB, LDH and AST). The heart was harvested for histopathological studies.

\section{Biochemical analysis}

The serum activities of the creatine kinase isoenzyme, CKMB and LDH were determined using enzyme immunoassay method as described by Tietz (5). AST was determined using colorimetric method. 5

\section{Histopathological analysis}

The excised heart and kidney tissues were processed using the paraffin wax embedding technique, sectioned at 5 microns and stained using the Haematoxylin and Eosin $[\mathrm{H}$ and E] staining procedure. ${ }^{6}$ The histological sections were examined using an Olympus TM light microscope.

\section{Statistical analysis}

Data analysis was done using GraphPad prism version 7.0 (GraphPad, San Diego, CA, USA). The results of the biochemical assays were reported as mean \pm SEM (standard error of mean). One way analysis of variance (ANOVA), followed by the Tukey post hoc analysis, was used to test for the level of significance $(\mathrm{p}<0.05)$.

\section{RESULTS}

\section{Phytochemical results.}

The result of the preliminary phytochemical analysis of Nigella sativa revealed abundant presence of alkaloids and flavonoids $(+++)$; moderate presence of tannins and phenols $(++)$. However glycosides, saponins and steroids were absent.

\section{Biochemical results}

The functionality of the heart was established by estimating the serum level of CK-MB (U/L), LDH (U/L) and AST (U/L). A statistically significant $(\mathrm{P}<0.05)$ elevated levels of $\mathrm{CK}-\mathrm{MB}$ (U/L), LDH (U/L) and AST (U/L), were seen in $\mathrm{CdCl}_{2}$-treated group B (negative control) when compared with group A (normal control) and group E (positive control). However, co-administration of $\mathrm{CdCl}_{2}$ with high and low doses of methanolic extracts of Nigella sativa (MENS) separately, restored the level of these parameters to near normal when compared with $\mathrm{CdCl}_{2}$-treated group (negative control). Furthermore, we observed the extracts had a dosedependent protection, with the low dose MENS showing better cardioprotection than high dose MENS (Table 1).

Table 1: Statistical Comparison of cardiac biomarkers of treated groups with negative controls

\begin{tabular}{|c|c|c|c|}
\hline Groups & CK-MB (U/L) & LDH (U/L) & AST (U/L) \\
\hline A: Normal Control & $193.75 \pm 11.09^{* *}$ & $195.03 \pm 14.72^{* *}$ & $20.51 \pm 3.69^{*}$ \\
\hline B: $\mathbf{C d C l}_{\mathbf{2}}$ Alone & $255.08 \pm 20.82$ & $254.75 \pm 13.05$ & $40.75 \pm 10.92$ \\
\hline C: $\mathbf{C d C l}_{\mathbf{2}}+\mathbf{M E N S ~ ( 3 0 0 m g / k g )}$ & $201.81 \pm 13.77^{*}$ & $200.75 \pm 15.32^{* *}$ & $21.13 \pm 4.33^{*}$ \\
\hline D: $\left.\mathbf{C d C l}_{\mathbf{2}}+\mathbf{M E N S ~} \mathbf{6 0 0 m g} / \mathbf{k g}\right)$ & $235.55 \pm 20.62$ & $227.75 \pm 22.75$ & $34.09 \pm 5.24$ \\
\hline E: $\mathbf{C d C l}_{\mathbf{2}}+$ Vit. C $\mathbf{2 0 0 m g / k g )}$ & $200.12 \pm 18.26^{*}$ & $199.51 \pm 15.42^{* *}$ & $20.88 \pm 4.37^{*}$ \\
\hline
\end{tabular}

Values given as Mean $\pm \mathrm{SD} .{ }^{* *} \mathrm{p}<0.01$ or ${ }^{*} \mathrm{p}<0.05$ is significant when $\mathrm{CdCl}_{2}$ alone (negative control) is compared with all other groups. 


\section{Histopathological results.}

In Figure 1, the heart of normal control rats appeared functionally and structurally normal. The cardiac fibres showed a well conserved morphology (1A). The heart of $\mathrm{CdCl}_{2}$-treated group (negative control) showed abnormal changes; there was evidence of fibrosis and mild infiltration by inflammatory cells (1B). However, the cardiac fibres of test group rats (low dose MENS at $300 \mathrm{mg} / \mathrm{kg}$ ) appeared normal with very mild infiltration by inflammatory cells (1C). While other test group rats (high dose MENS at $600 \mathrm{mg} / \mathrm{kg}$ ) showed sections that are fairly damaged (1D). Furthermore, photomicrograph of heart section from Vitamin C group $(200 \mathrm{mg} / \mathrm{kg})$, showed normal appearance of cardiac fibres (1E).
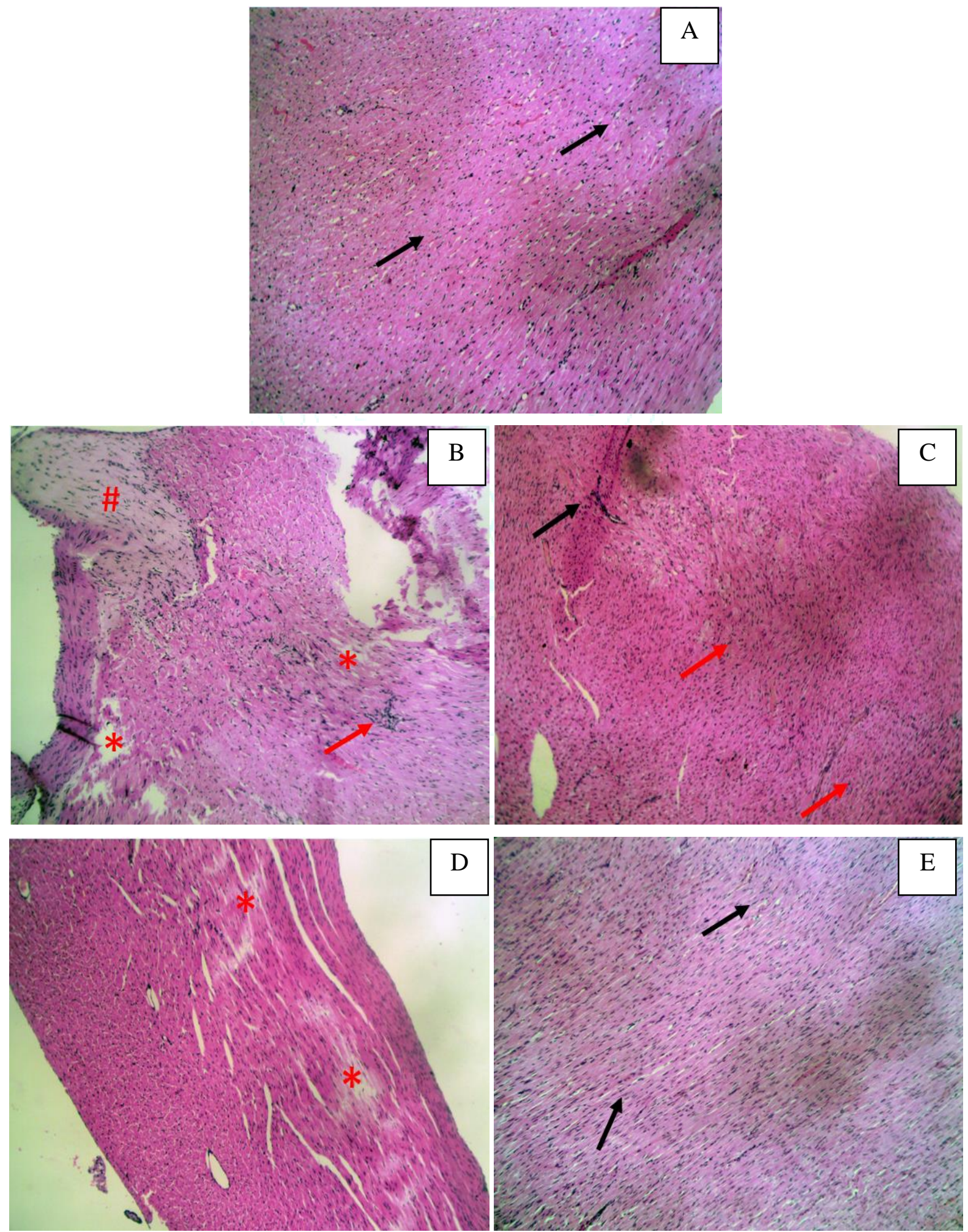

Figure 1: Photomicrograph of heart section. (A) Cardiac fibres (arrows) appear normal with no degenerative changes. (B) Evidence of fibrosis (\#) and mild infiltration by inflammatory cells (arrows). Some fibres are also damaged $\left({ }^{*}\right)$. (C) Cardiac fibres (red arrow) appear normal with very mild infiltration by inflammatory cells (black arrows). (D) Some sections of the cardiac fibres are damaged $(*)$. (E) Cardiac fibres appear normal (arrows). [Stain: H and E; $\times 100]$. 


\section{DISCUSSION}

Accumulation of toxic substances such as drugs, heavy metals, poisons etc can cause significant damage to the heart muscles. Exposure to cadmium could produce serious adverse effects in humans and one of the ways through which this happens is through induction of oxidative stress; whereby it induces early hyperproduction of Reactive Oxygen Species (ROS) that impairs antioxidant defense system, leading to oxidative stress in target organs and tissues. $^{7}$

The morbidity and mortality rate associated with the acute myocardial infarction can be evaluated using biochemical markers of cardiac function in assessing heart diseases. Generally, Cardiac marker enzymes such as CK-MB, AST and LDH are very low in serum. They are intracellularly located in the cells of the heart. Disruption of these enzymes via the cell membrane makes them to leak out into plasma and increase tremendously, which give out information of the extent of myocardial injury due to oxidative stress and lipid peroxidation. ${ }^{8}$

Thus, in this study, the functionality of the heart was established by estimating the serum level of CK-MB (U/L), $\mathrm{LDH}(\mathrm{U} / \mathrm{L})$ and AST (U/L). Treatment with $\mathrm{CdCl}_{2}$ in group B showed a statistically significant $(\mathrm{P}<0.05)$ elevated levels of CK-MB (U/L), LDH (U/L) and AST (U/L) when compared with group A (normal control) and group E (positive control). This observation supports the general knowledge of the cardiotoxic effect of cadmium. We observed a dose dependent protection by the seed extract; and this once against supports the world wide claim that N.sativa is a potent medicinal plant.

Over the years, scientists have been researching on food and plant products that possess protective effects against cardiotoxicity. It was discovered that diets rich in natural antioxidants (especially flavonoids) have potent effects against oxidative stress caused by cardiotoxic substances. ${ }^{9}$ Thymoquinone, an active ingredient of Nigella sativa (black seed), is a constituent of flavonoids. Flavonoids are natural antioxidants that occur in fruits, vegetables flowers and seeds which are very important in human diet. ${ }^{9}$ Flavonoids have high antioxidant effects and consequently anti- free radical effects. They have the ability to reduce free radical formation and to scavenge free radicals from blood, thereby preventing cell injury. ${ }^{9}$ The result of the preliminary phytochemical analysis of Nigella sativa (black seed) revealed abundant presence of alkaloids and flavonoids $(+++)$; moderate presence of tannins and phenols $(++)$. The findings we observed could be as a result of the singular or combined actions of one or more phytochemical constituents present in the Nigella sativa.

According to Kooti et al.10, long term oral administration of $N$. sativa may decrease vascular contractile responsiveness and some cardiovascular complications in diabetes. Observation from the biochemical and histological results show that consumption of $N$. sativa may serve as a healthy diet and as well be an effective intervention in improving cardiac injuries. This study and other previous reports suggest a protective role of dietary $N$. sativa intake against cardiotoxicity.

\section{CONCLUSION}

The findings of this work show that cadmium induced cardiotoxicity in albino rats. The administration of methanolic extract of Nigella sativa (MENS) (Black seed) ameliorated the effects in the test groups, although in a dosedependent manner. Thus, the result suggests that methanolic extract of MENS has anti-cardiotoxic properties and could therefore offer significant protection against cardiac injuries.

\section{COMPETING INTERESTS STATEMENT}

The authors declare no conflicts of interest.

\section{REFERENCES}

1. Shen J, Wang X, Zhon D, Li T, Tang L, Gong T, Su J, Liang P. Modelling cadmium-induced cardiotoxicity using human pluripotent stem cell-derived cardiomyocetes. Journal of Cellular and Molecular Medicine. 2018; 22(9):4221- 4235.

2. Ajibesin KK. Dacryodes edulis (G. Don) HJ. Lam: A review on its medicinal, phytochemical and economic properties. Research Journal of Medicinal Plant 2011; 5(1):32-41.

3. Babaei HA, Motamedifar M, Khalifat S, Mohammadi A, Khosrow Z, Motamedifar A. In vitro study of antibacterial property and cytotoxic effects of aqueous, ethanolic, methanolic, and hydroalcoholic extracts of fenugreek seed. Pakistan Journal of Medical and Health Science. 2018; 12(2):906-910.

4. Trease G, Evans SM. Pharmacognosy: (15 th Edition). English Language Book Society. Bailliere Tindall, London, 2002. p. 2367.

5. Tietz NW. Clinical Guide to Laboratory Tests, $3^{\text {rd }}$ edition W. B. Saunders, co, Philadelphia, 1995; 216-217.

6. Baker FJ, Silverton RE, Pallister CJ Baker and Silverton's Introduction to Laboratory Technology. 7th Edition, Butterworth-Heinemann, Wobrun, MA, USA, 1998; page 448.

7. Erdem O, Yazihan N, Kocak MK, Sayal A, Akcil E. Influence of chronic cadmium exposure on the tissue distribution of copper and zinc and oxidative stress parameters in rats. Toxicology and Industrial Health. 2015; 32(8):1505-1514.

8. Pradeepkumar B, Sudheer A, Reddy TS, Reddy KS, Narayana G, Veerab-hadrappa K. Cardioprotective activity of flavonoid fraction of gymnema sylvestre leaves on doxorubicin induced cardiac damage. Journal of Young Pharmacists. 2018; 10(4):422-426.

9. Panche AN, Diwan AD, Chandra SR. Flavonoids: an overview. Journal of Nutritional Science, 2016; 5:1-15.

10. Kooti W, Hasanzadeh-Nooti Z, Sharafi-Ahvazi N, Asadi-Samani M, Ashtary-Larky D. Phytochemistry, Pharmacology and therapeutic uses of black seed (Nigella Savita). Chinese Journal of Natural Medicines. 2016; 14(10):732-745. 